\title{
MATHEMATICAL MODELLING OF MACROSEGREGATION IN INGOT CASTING
}

\begin{abstract}
M. O. Assunção Jra and M. Vynnycky

${ }^{\text {a}}$ Universidade de São Paulo

Departamento de Matemática Aplicada e Estatística São Carlos, SP, Brasil assuncao@icmc.usp.br ${ }^{\mathrm{b}} \mathrm{KTH}$ Royal Institute of Technology Department of Materials Science and Engineering. Division of Processes Stockholm, Sweden michaelv@kth.se Received: April 16, 2018 Revised: May 09, 2018 Accepted: October 15, 2018

ABSTRACT

The occurrence of macrosegregation in alloys produced by ingot casting can adversely affect the quality of the final product. Macrosegregation can be described as a severe variation on the macroscopic scale of the chemical species that compose the alloy, and the ability of computational simulations to predict such defects remains far from perfect. Therefore, this research focuses on the development of a two-dimensional mathematical model that through computational simulations - could be applied to study and predict the formation of macrosegregation in the ingot casting of binary alloys. Once accomplished, this work can establish the framework to new studies that will tackle more advanced problems, e.g., for actual ingot geometries, three-dimensional models and industrially-important ternary alloys.

Keywords: mathematical modeling; ingot casting; solidification; macrosegregation
\end{abstract}

\section{NOMENCLATURE}

c solute concentration, wt $\%$

$\mathrm{C}_{\mathrm{p}} \quad$ specific heat, $\mathrm{J} /(\mathrm{kg} . \mathrm{K})$

D diffusion coefficient

$\mathrm{Ga}$ Galilei number

$\mathrm{K}_{\mathrm{p}} \quad$ partition coefficient

$\mathrm{L}_{\text {at }} \quad$ latent heat of fusion, $\mathrm{J} / \mathrm{kg}$

Le Lewis number

Pr Prandtl number

Ra Rayleigh number

St Stefan number

$\mathrm{T}$ temperature, $\mathrm{K}$

u fluid velocity, $\mathrm{m} / \mathrm{s}$

\section{Greek symbols}

$\alpha^{\prime} \quad$ thermal expansion coefficient

$\Gamma \quad$ slope of liquidus line

$\kappa \quad$ thermal conductivity, $\mathrm{W} /(\mathrm{m} . \mathrm{K})$

$\mu \quad$ dynamic viscosity, $\mathrm{Ns} / \mathrm{m}^{2}$

$\rho$ density, $\mathrm{kg} / \mathrm{m}^{3}$

$\tau \quad$ dimensionless time

$\chi \quad$ liquid fraction

\section{Subscripts}

$0 \quad$ reference value

1 liquid-phase quantity

$\mathrm{m}$ mixture quantity

s solid-phase quantity

\section{INTRODUCTION}

Ingots are single blocks of metal, typically steel and weighing from a few kilos to a few tons, which are created by means of a casting procedure where molten metal is fed into cooling mold. There, it is left until it completely solidifies. The applications for ingot casting include, according to P. Patil and Balasubramanian (2015), forging die blocks, heavy equipment, ship engine parts, pressure vessel parts, oil well equipment, turbine rotors, valve bodies, auto shafts, etc.

To model the solidification process with the aid of computational simulations may help to reduce the cost of production and prevent defects such as macrosegregation. These are basically differences in concentration over a length scale of the ingot itself. They are defects whose formation a severity is very sensitive to the casting procedure and the ingot size (Pickering, 2013).

It is understood that the causes of macrosegregation are related, according to (Flemings, 1974), to the movement of liquid and solid inside the mushy zone. Highly segregated phases (with great differences in concentration) can be found in this region during the solidification process; it is the physical displacement of these phases that induces macrosegregation. Among other kinds of macrosegregation, the A-segregation, as stated in (Fredriksson and Åkerlind, 2006), is caused by natural convection in the molten metal, which in turn is driven by a density gradient. This kind of segregation importantly concerns high pressure 
vessels manufacturers: the vessels are built through the removal of the internal portion of a steel ingot, followed by the installation of metallic parts on its interior by welding. However, the procedure's integrity is worsened if the weld matches with Asegregated regions, which are characteristically stiffer, but have less tenacity (Maidorn and Blind, 1985). If exposed during forging or rolling operations to which this product is submitted, the whole ingot must sometimes be discarded.

\section{Computational Procedure}

One simple approach to model macrosegregation is to formulate a set of equations valid on all the regions mentioned before - the solid, liquid and mush; this is categorized as a singledomain approach. Another approach is to develop equations for each one of the domains separately. The advantage of the former over the latter is that there is no need to track the solid/mush and mush/liquid moving boundaries that could develop with complex shapes as the simulation proceeds. This simplification can be done following Amberg (1991), by including terms in the original equations to keep a balance between solid and liquid fractions. In the singledomain approach, it is then possible to write down the model considering the fundamental laws of mass, momentum, and energy conservation, plus thermodynamic relations valid for phase changes.

\section{Mathematical Expressions}

Assuming the solid and liquid phase densities to be equal, the velocity field may be obtained from a momentum balance valid in all three regions as

$$
\begin{aligned}
\nabla \cdot(\chi \mathrm{u})=0 & \\
\rho_{0}\left(\frac{\partial \mathrm{u}}{\partial \mathrm{t}}+\mathrm{u} \cdot \nabla \mathrm{u}\right)-\mu \nabla^{2} \mathrm{u} & =-\nabla \mathrm{p}-\rho \mathrm{g} \\
& -\frac{\mu}{\mathrm{H}(\chi)} \chi \mathrm{u}
\end{aligned}
$$

In Eq. (2), $\rho_{0}$ is the density in $\left[\mathrm{kg} / \mathrm{m}^{3}\right]$ and refers to initial liquid state, while the local density $\rho$ can be written as a function of temperature and concentration measured in a certain control volume, such relation may be presented as soon as the solute concentration is adequately defined. The vector $u$ is the velocity, written in $[\mathrm{m} / \mathrm{s}]$; moreover, the velocity in the mush must be understood as an average among velocities inside porous domain. $\mu$ is the dynamic viscosity in $\left[\mathrm{Ns} / \mathrm{m}^{2}\right]$, the pressure $\mathrm{p}$ is given in $\left[\mathrm{N} / \mathrm{m}^{2}\right], \mathrm{g}$ stands for gravity $\left(9.8 \mathrm{~m} / \mathrm{s}^{2}\right), \chi$ represents the liquid fraction, which means the unsolidified portion inside a control volume, in a range from 0 (solid) to 1 (liquid).

Here, the permeability $\mathrm{H}(\chi)$ measures, as stated by (Fredriksson and Akerlind, 2006), the ability of the liquid to penetrate through the dendrites of a region where the solidification process has begun and can be given by expressions presented in (West, 1985).

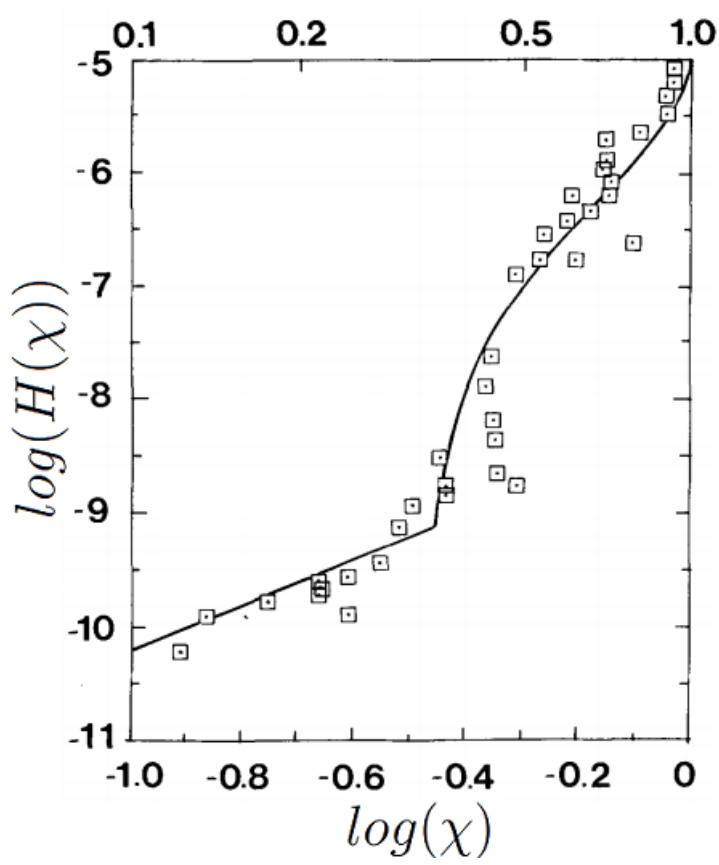

Figure 1. Permeability vs liquid fraction, squares represent the experimental data and the solid line is the function used to predict the permeability.

$$
\mathrm{H}(\chi)=\mathrm{Y}_{1} \mathrm{~K}_{1}+\mathrm{Y}_{2} \mathrm{~K}_{2}
$$

where $\mathrm{K}_{1}=\chi^{2}$, and

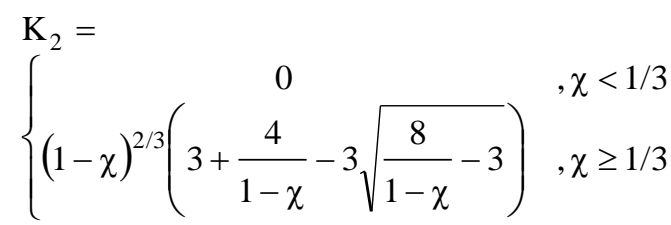

The permeability is described as a function of liquid fraction in accordance to the applicability to the mush zone of metallic alloys, such expressions are given in Eq. (3) and behaved well when compared to experimental data obtained by the author, as exhibited in Fig.1.

It can be observed that while the solidification process did not start in a certain region, i.e. $(\chi=1)$, then the last term on right-hand side of Eq. (2) vanishes, leaving the usual Navier-Stokes equation.

Once the solidification has started, the term gains importance in the equation, whilst the velocity tends to zero making the terms on the left-hand side of the equation negligible.

The parameters $Y_{1}$ and $Y_{2}$ are constants obtained by experiments carried in (Piwonka and Flemings, 1966), in which the values were found to be $Y_{1}=$ 
$6.4 \mathrm{e}-9 \mathrm{~cm}^{2}$ and $Y_{2}=8.8 \mathrm{e}-7 \mathrm{~cm}^{2}$.

The temperature in each control volume can be obtained from the basic heat equation in terms of a unique temperature, T, valid for liquid, mushy and solid regions:

$$
\rho_{0} \mathrm{C}_{\mathrm{p}}\left(\frac{\partial \mathrm{T}}{\partial \mathrm{t}}+\chi \mathrm{u} \cdot \nabla \mathrm{T}\right)=\nabla \cdot(\kappa \nabla \mathrm{T})-\mathrm{L}_{\mathrm{at}} \frac{\partial \chi}{\partial \mathrm{t}}
$$

where $C_{p}$ is the specific heat in $[\mathrm{J} /(\mathrm{kg} \cdot \mathrm{K})], \kappa$ is the thermal conductivity in $[\mathrm{W} /(\mathrm{m} . \mathrm{K})]$, while $\mathrm{L}$ at represents the latent heat of fusion $[\mathrm{J} / \mathrm{kg}] . \kappa$ can be written as

$$
\kappa=\chi \kappa_{1}+(1-\chi) \kappa_{\mathrm{s}}
$$

which constitutes a linear interpolation between the thermal conductivities of the solid and liquid phases.

The boundary conditions considered in problems of this nature may vary depending on the authors approach.

$$
-\kappa \frac{\partial \mathrm{T}}{\partial \mathrm{n}}=\mathrm{q}
$$

Here, the classical Fourier law stated in Eq. (7) was adopted. It poses the heat flux $\mathrm{q}\left[\mathrm{W} / \mathrm{m}^{2}\right]$ as proportional to the magnitude of the temperature gradient and opposite to it in sign, with $\kappa$ as the constant of proportionality. Lienhard IV and Lienhard V (2017), where $\mathrm{n}$ is the vector normal to the boundary to which this boundary condition is applied. This configures a Neumann boundary condition used to define the heat exchange of the ingot surface with its surroundings.

The mass conservation for the solute may be obtained, according to Amberg (1991), as

$$
\frac{\partial \mathrm{c}_{\mathrm{m}}}{\partial \mathrm{t}}+\nabla \cdot\left(\mathrm{u} \chi \mathrm{c}_{1}\right)=\mathrm{D} \nabla^{2} \mathrm{c}_{\mathrm{m}}
$$

with diffusion coefficient $\mathrm{D}$, where $\mathrm{c}_{1}$ represents the local solute concentration in the metallic alloy, $\mathrm{c}_{\mathrm{m}}$ is the mixture solute concentration obtained as a balance between the concentrations for liquid and solid phase, $\mathrm{c}_{\mathrm{l}}$ and $\mathrm{c}_{\mathrm{s}}$ respectively, in the form

$$
\mathrm{c}_{\mathrm{m}}=\chi \mathrm{c}_{1}+(1-\chi) \mathrm{c}_{\mathrm{s}}
$$

In addition, $c_{s}$ and $c_{1}$ are related to each other from the phase diagram (for the Fe-c system in the case of steel with no additional elements) by $\mathrm{c}_{\mathrm{s}}=\mathrm{K}_{\mathrm{p}} \cdot \mathrm{c}_{1}$ with $\mathrm{K}_{\mathrm{p}}$ as the partition coefficient.

The boundary condition imposed here was the zero flux for the whole domain boundary, which appropriately means that there is no transport of solute across the walls.
The boundary condition imposed here was the zero flux for the whole domain boundary, which appropriately means that there is no transport of solute across the walls.

Now, it is possible to define an appropriate way to write the density $\rho$ like a function of temperature and concentration as

$$
\rho=\rho_{0}\left(1+\alpha^{\prime}\left(T-T_{0}\right)+f_{1}\right)
$$

Where $\mathrm{T}_{0}$ is the melting temperature for pure iron ( $0 \%$ carbon), and

$$
\alpha^{\prime}=\frac{\mathrm{d}}{\mathrm{e}+100 \mathrm{c}_{1}}
$$

where the numerical parameters $\mathrm{d}, \mathrm{e}, \mathrm{f}$ are given by Olsson (1980) and are presented in Tab. 1.

Table 1. Physical parameters adopted in the simulations.

\begin{tabular}{|c|c|c|}
\hline Variable & Value & Units \\
\hline $\mathrm{Cp}$ & 753 & $\mathrm{~J} /(\mathrm{kg} . \mathrm{K})$ \\
\hline $\mathrm{D}$ & $1 \mathrm{e}-9$ & $\mathrm{~m}^{2}$ \\
\hline $\mathrm{d}$ & $-4.2 \mathrm{e}-4$ & 1 \\
\hline $\mathrm{e}$ & 0.55 & 1 \\
\hline$\varepsilon$ & $1 \mathrm{e}-6$ & 1 \\
\hline $\mathrm{f}$ & -8 & 1 \\
\hline $\mathrm{g}$ & 9.8 & $\mathrm{~m} / \mathrm{s}^{2}$ \\
\hline$\Gamma$ & 7800 & ${ }^{\circ} \mathrm{C} / \mathrm{wt}$ \\
\hline$\kappa_{\mathrm{l}}$ & 30 & $\mathrm{~W} /(\mathrm{m} . \mathrm{K})$ \\
\hline $\mathrm{K}_{\mathrm{p}}$ & 0.42 & 1 \\
\hline$\kappa_{\mathrm{s}}$ & 60 & $\mathrm{~W} /(\mathrm{m} . \mathrm{K}$ \\
\hline $\mathrm{L}$ & 0.1 & $\mathrm{~m}$ \\
\hline $\mathrm{L}_{\mathrm{at}}$ & $2.72 \mathrm{e} 5$ & $\mathrm{~J} / \mathrm{kg}$ \\
\hline$\mu$ & $6.94 \mathrm{e}-3$ & $\mathrm{~N} \mathrm{~s} / \mathrm{m}^{2}$ \\
\hline$\rho_{0}$ & 6940 & $\mathrm{~kg} / \mathrm{m}^{3}$ \\
\hline $\mathrm{q}$ & 60 & $\mathrm{~kW} / \mathrm{m}^{2}$ \\
\hline $\mathrm{T}_{0}^{\mathrm{a}}$ & 1538 & ${ }^{\circ} \mathrm{C}$ \\
\hline
\end{tabular}

${ }^{a}$ from Fig. 2

Observe that there is no explicit partial differential equation for $\chi$; instead, its local value in the mushy region is given implicitly by the relation $\mathrm{T}=\mathrm{T}_{1}\left(\mathrm{c}_{1}\right)$, where $\mathrm{T}_{1}$ is the liquidus temperature, determined as a function of $c_{1}$ from the phase diagram. An artificial way to ensure that this relation is satisfied is to introduce the equation

$$
\frac{\partial \chi}{\partial \mathrm{t}}=\frac{1}{\varepsilon}\left(\mathrm{T}-\mathrm{T}\left(\mathrm{c}_{1}\right)\right)
$$

as in Amberg (1991); here, is chosen as an arbitrarily small parameter. The afore mentioned relation to $T_{1}$ is given by

$$
\mathrm{T}_{1}\left(\mathrm{c}_{1}\right)=\mathrm{T}_{0}-\Gamma \mathrm{c}_{1}
$$




\section{Ciência/Science}

where $T_{0}$ is again the melting temperature of pure iron, and $\Gamma$ is proportionality constant represented by the slope of the line in the phase diagram in Fig. 2.

\section{COMPUTATIONAL IMPLEMENTATION}

The methodology applied in the task of solving the previous set of equation, was to make use of Marker and Cell Method (MAC), whose key feature is to proceed to the spatial discretization using a Finite Volume Method over a staggered mesh. The momentum equation is solved by decoupling the velocities and pressure variables by the Projection Method, while the Adams-Bashforth/Crank-Nicolson $(\mathrm{ABCN})$ method to make the temporal numerical integration.

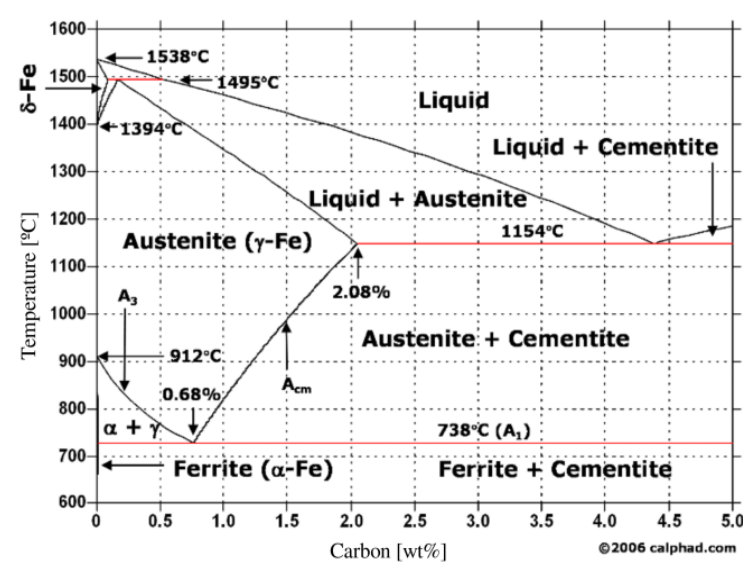

Figure 2. Phase diagram for $\mathrm{Fe}-\mathrm{C}$ alloy.

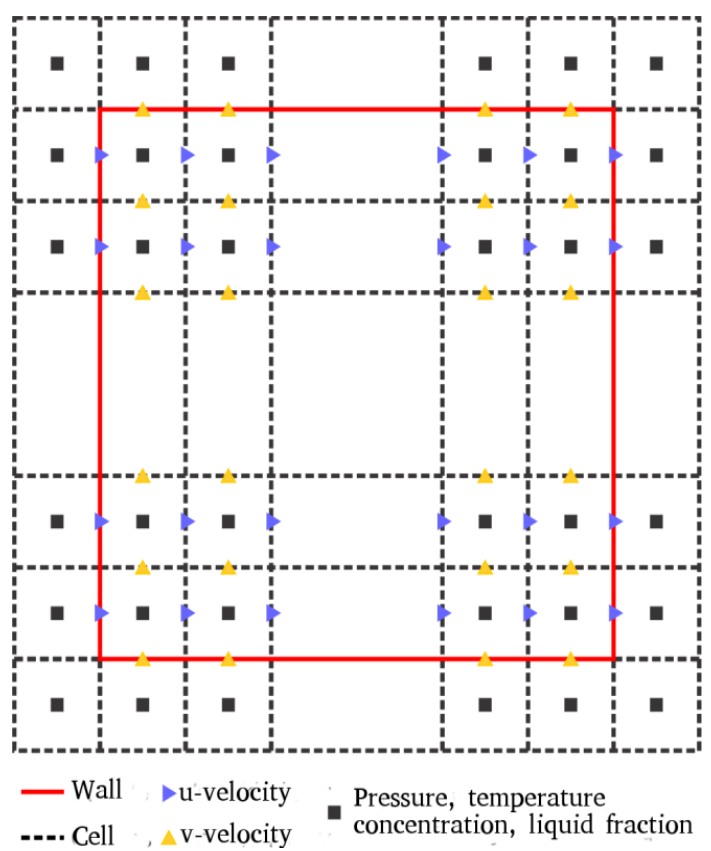

Figure 3. Cell representation for the staggered grid used in the MAC approach. $\mathrm{u}$ and $\mathrm{v}$ are the $\mathrm{x}$ and $\mathrm{y}$ components of $\mathrm{u}$, respectively.
Assunção Jr and Vynnycky. Mathematical Modelling...

The discretization follows the scheme presented in (Prosperetti and Tryggvason, 2007) and (http://www.lcad.icmc.usp.br/ buscaglia/teaching/, 1 Oct. 2015), with centered control volumes for each of the variables in the problem - $\mathrm{u}, \mathrm{p}, \mathrm{T}$ and $\mathrm{c}_{1}-$ as illustrated in Fig. 3.

The numerical methods described above were implemented through an in-house script making use of MATLAB programming environment.

\section{RESULTS AND DISCUSSION}

The model consisting on the equations presented in Section 2. was non-dimensionalized using the following scales

$$
\begin{gathered}
{[\mathrm{x}]=\mathrm{L}, \quad[\mathrm{u}]=\frac{\alpha}{\mathrm{L}}, \quad[\mathrm{t}]=\frac{\mathrm{L}^{2}}{\alpha}, \quad[\mathrm{T}]=\frac{\mathrm{qL}}{\kappa},} \\
{[\mathrm{p}]=\frac{\rho_{0} \alpha^{2}}{\mathrm{~L}^{2}}, \quad[\mathrm{c}]=\mathrm{c}_{0}}
\end{gathered}
$$

where

$$
\alpha=\frac{\kappa}{\rho C_{p}}
$$

and $c_{0}$ is the initial solute concentrations. Replacing the dimensional variables in the original equations and doing the algebra, allows us to identify some classical adimensional numbers used to characterize systems with fluid flow, heat and mass transfer, such as

$$
\begin{gathered}
\operatorname{Pr}=\frac{v}{\alpha}, \quad \mathrm{Ra}=\frac{\mathrm{L}^{3} \beta \Delta \mathrm{Tg}}{\alpha \nu}, \quad \mathrm{St}=\frac{\mathrm{C}_{\mathrm{p}} \Delta \mathrm{T}}{\mathrm{L}_{\mathrm{at}}}, \\
\mathrm{Ga}=\frac{\mathrm{L}^{3} \mathrm{~g}}{v^{2}}, \quad \mathrm{Le}=\frac{\alpha}{\mathrm{D}}
\end{gathered}
$$

which are known as Prandtl, Rayleigh, Stefan, Galilei, and Lewis number, respectively. Applying the relations from Eq. (13), and considering the Eq. (1)-(4) we obtain the non-dimensional equation for momentum

$$
\begin{aligned}
\frac{\partial \mathrm{u}^{*}}{\partial \tau}+\mathrm{u}^{*} \bar{\nabla} \mathrm{u}^{*}-\operatorname{Pr} \bar{\nabla} \mathrm{u}^{*} & = \\
& -\bar{\nabla}^{*}-\frac{\mathrm{L}^{2}}{[\mathrm{H}]} \operatorname{Pr} \frac{\chi}{\mathrm{H}(\chi)} \mathrm{u} \\
& +\operatorname{RaPr} \alpha^{\prime}\left(\mathrm{T}^{*}-\frac{\mathrm{T}_{0}}{[\mathrm{~T}]}\right) \mathrm{e}_{\mathrm{y}} \\
& +\operatorname{GaPr}^{2}\left(\mathrm{fc}_{1}\right) \mathrm{e}_{\mathrm{y}}
\end{aligned}
$$

where the $\operatorname{star}(*)$ denotes the variable on its non- 


\section{Ciência/Science}

dimensional form. Proceeding in the same way for the heat transfer, now non-dimensionalizing the Eq. (5), leads to:

$$
\frac{\partial \mathrm{T}^{*}}{\partial \tau}+\chi \mathrm{u}^{*} \cdot \bar{\nabla} \mathrm{T}^{*}=\bar{\nabla}^{2} \mathrm{~T}^{*}-\frac{1}{\mathrm{St}} \frac{\partial \chi}{\partial \tau}
$$

Finally, the non-dimensionalized form of Eq. (8) to model the solute conservation becomes:

$$
\frac{\partial \mathrm{c}_{\mathrm{m}}}{\partial \tau}+\mathrm{u}^{*} \chi \bar{\nabla} \mathrm{c}_{1}^{*}-\frac{1}{\mathrm{Le}} \bar{\nabla}^{2} \mathrm{c}_{1}^{*}=0
$$

The solution for the non-dimensionalized set of equations and adequate boundary conditions was approximated by computation simulation applying the presented methodology in a domain $20 \mathrm{~cm}$ wide and $10 \mathrm{~cm}$ high, with insulated top and bottom walls, cooling from the sides at the same given rate q. Thus, horizontal symmetry is assumed and the dependent variables: temperature, pressure, velocities, concentration and liquid fraction are computed for just half of the original domain. The other parameters used in the simulation can be found in Tab. 1.

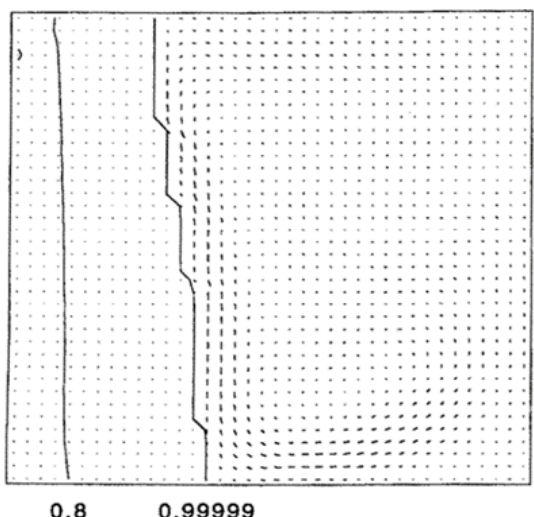

Figure 4a. Liquid fraction after $200 \mathrm{~s}$ as presented in Amberg (1991).

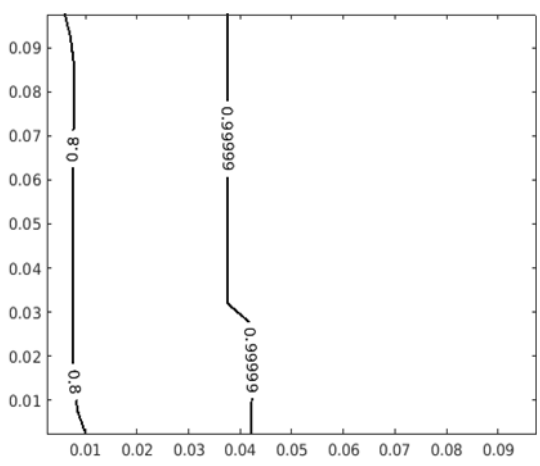

Figure $4 b$. Liquid fraction after $200 \mathrm{~s}$ obtained by authors.

The resulting liquid fraction after 200 s of solidification is shown in Fig. 4(a)-4(b) with contour lines drawn across the domain.

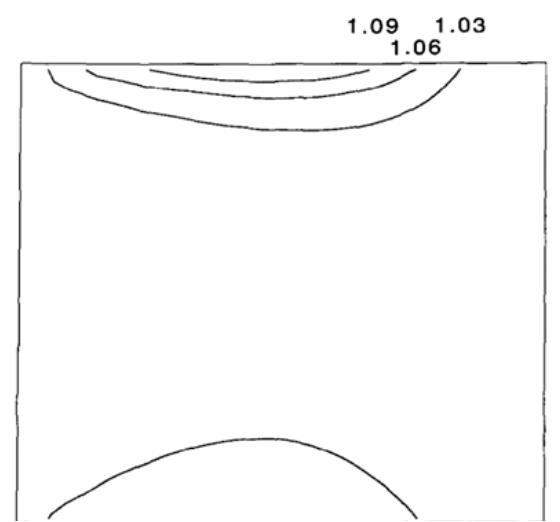

Figure 5a. Solute concentration after 1800s as presented in Amberg (1991).

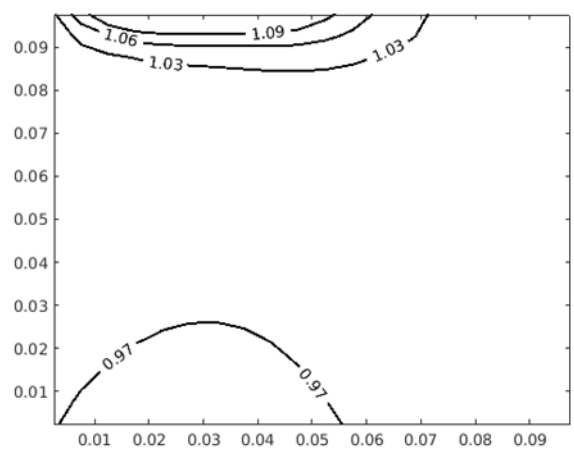

Figure $5 b$. Solute concentration after 1800 s obtained by authors.

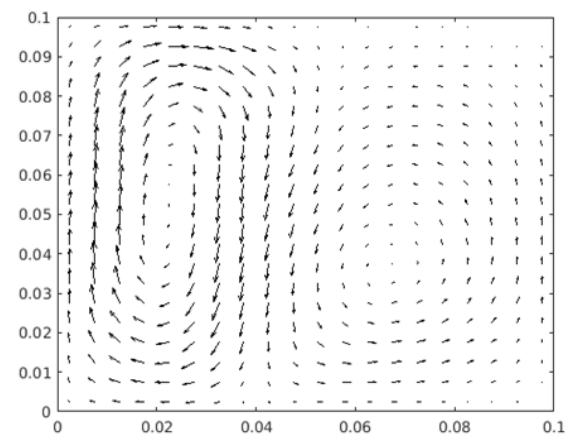

Figure 6a. Velocity field for the domain half occupied by mush, half occupied by liquid phase, at an early stage of solidification process.

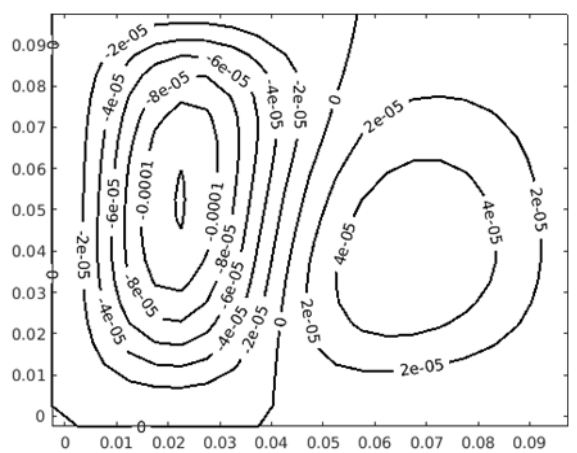

Figure $6 \mathrm{~b}$. Streamlines obtained from the velocity field from Fig.6(a). 
Figures 5(a)-5(b) compares the solute composition of the binary Fe-C alloy after 6000s of solidification, both images show relatable differences in concentrations obtained across de domain, with lower concentration at the bottom and higher concentration at the top. Figure 6(a) illustrates the deceleration of velocity field for the region with lower liquid fraction, while Fig. 6(b) shows the corresponding streamlines.

\section{CONCLUSIONS}

It can be noticed, that the regions with constant values of liquid fraction are distributed across the domain, in accord with the expected results, while the macrosegregated regions were found in the simulation as in the original paper (Amberg, 1991): greater than average solute concentration in the upper region, and lower than average at the bottom. Besides that, the flow recirculation in the liquid region is in an opposite direction to that in the mushy region, also in accord with theory (Fredriksson and Akerlind, 2012).

\section{ACKNOWLEDGEMENTS}

M. Assunção acknowledges the support provided by FAPESP through the process n.2016/12678-0.

\section{REFERENCES}

Amberg, G., 1991, Computation of Macrosegregation in an Iron-Carbon Cast, International Journal of Heat and Mass Transfer, Vol. 34, pp. 217-227.

Flemings, M., 1974, Solidification Processing, Materials Science and Engineering Series, McGrawHill.

Fredriksson, H., and Åkerlind, U., 2006, Materials Processing, 1st Edition, John Wiley and Sons Ltd.

Fredriksson, H., and Åkerlind, U., 2012, Solidification and Crystallization Processing in Metals and Alloys, 1st Edition, Wiley, New Jersey.

Lienhard IV, J., and Lienhard V, J., 2017, A Heat Transfer Textbook, 4th Edition, Phlogiston Press, Cambridge, MA.

Maidorn, C., and Blind, D., 1985, Solidification and Segregation in Heavy Forging Ingots, Nuclear Engineering and Design, Vol. 84, pp. 285-296.

Olsson, A., 1980, Department of Casting of Metals, Doctoral Thesis, Royal Institute of Technology, Stockholm, Sweden.

Patil, P., Nalawade, R., Balachandran, G., and Balasubramanian, V., 2015, Analysis of Solidification Behavior of Low Alloy Steel Ingot Casting - Simulation and Experimental Validation, Ironmaking and Steelmaking, Vol. 42, pp. 512-524.

Pickering, E. J., 2013, Macrosegregation in
Steel Ingots: the Applicability of Modelling and Characterization Techniques, ISIJ International, Vol. 53, pp. 935-949.

Piwonka, T., and Flemings, M., 1966, Pore Formation in Solidification, Transactions of the Metallurgical Society of AIME, Vol. 236, No. 8, pp. 1157-1165.

Prosperetti, A., and Tryggvason, G., 2007, Computational Methods for Multiphase Flow, 1st Edition, Cambridge University Press.

West, R., 1985, On the Permeability of the Two-Phase Zone During Solidification of Alloys, Metallurgical Transactions A, Vol. 16, pp. 693-693. 